\title{
Theta Rhythmic Clock-Like Activity of Single Units in the Mouse Hippocampus
}

\author{
니 Zuang, ${ }^{1 *}$ Xiaoyu Ma, ${ }^{1 *}$ Guifen Chen, ${ }^{1}$ Edi Barkai, ${ }^{2}$ and Longnian Lin ${ }^{1}$ \\ ${ }^{1}$ Key Laboratory of Brain Functional Genomics (Ministry of Education and Shanghai), Institute of Brain Functional Genomics, School of Life Science and \\ the Collaborative Innovation Center for Brain Science, East China Normal University, Shanghai 200062, People's Republic of China, and ²Sagol Department \\ of Neurobiology, Faculty of Natural Sciences, University of Haifa, Haifa 31905, Israel
}

Theta rhythmic clock-like activity was observed in a small group of hippocampal CA1 neurons in freely behaving mice. These neurons were only persistently activated during theta states of waking exploration and rapid eye movement sleep, but were almost silent during the non-theta state of slow-wave sleep. Interestingly, these cells displayed a theta clock-like simple-spike firing pattern, and were capable of firing one spike per theta cycle during theta states. This is the first report of a unique class of hippocampal neurons with a clock-like firing pattern at the theta rhythm. We speculate that these cells may act as a temporal reference to participate in the theta-related temporal coding in the hippocampus.

Key words: clock-spiking; hippocampus; phase precession; theta oscillations

\section{Significance Statement}

Theta oscillations, as the predominant rhythms in the hippocampus during waking exploration and rapid eye movement sleep, may be critical for temporal coding/decoding of neuronal information, and theta-phase precession in hippocampal place cells is one of the best demonstrations of such temporal coding. Here, we show that a unique small class of hippocampal CA1 neurons fired with a theta rhythmic clock-like firing pattern during theta states. These firing characteristics support the notion that these neurons may play a critical role in theta-related temporal coding in the hippocampus.

\section{Introduction}

Physiological functions of neurons rely on their in vivo firing patterns. Thus, diverse neurons in different brain regions present various firing patterns. In the hippocampus of rodents, the most common neurons observed are place cells. They are pyramidal cells that become active when animals enter particular places in the environment (O'Keefe and Dostrovsky, 1971). The discharges of place cells are also characterized by temporal coding phenomena, such as theta phase locking and theta phase precession (Huxter et al., 2003). In addition, it was reported that certain neurons in the hippocampal CA1 encode concept (Quiroga et al., 2005; Lin et al., 2007), time (MacDonald et al., 2011), and other

\footnotetext{
Received 0ct. 23, 2015; revised March 16, 2016; accepted March 19, 2016.

Author contributions: L.Z. and L.L. designed research; L.Z., X.M., G.C., and L.L. performed research; L.Z., X.M., G.C., and L.L. analyzed data; L.Z., X.M., E.B., and L.L. wrote the paper.

This work was supported by the National Basic Research Development Program of China (Grant 2013CB835101), the National Natural Science Foundation of China (Grant 81271490), and the Basic Research Project of Shanghai Science and Technology Commission (Grants 14JC1401800 and 15JC1400102).

*L.Z. and X.M. contributed equally to this work.

The authors declare no competing financial interests.

Correspondence should be addressed to Longnian Lin, 3663 North Zhongshan Road, Shanghai 200062, People's Republic of China. E-mail: Inlin@brain.ecnu.edu.cn.

DOI:10.1523/JNEUROSCI.3851-15.2016

Copyright $\odot 2016$ the authors $\quad 0270-6474 / 16 / 364415-06 \$ 15.00 / 0$
}

information via their unique firing patterns. As for interneurons in the hippocampus, their firing activities often show relevance to hippocampal local field potential (LFP) rhythm, for example, the theta-locked neurons (Klausberger et al., 2003; Zhang et al., 2012), the gamma-locked neurons (Csicsvari et al., 2003), and the ripple-related neurons (Klausberger et al., 2003). These various firing patterns observed in rodent hippocampus in vivo are critical for describing the principles of hippocampal function and to reveal the mechanisms of information coding of hippocampal neurons.

To further study the firing properties of hippocampal neurons, we used drivable microelectrode arrays to record in freely behaving mice. We performed layer-by-layer recording in the hippocampal CA1 area (Lin et al., 2006). Previously, we observed not only the discharge activities of place cells, but also the firing patterns of a series of cells that had never been reported, including nest cells (Lin et al., 2007) and theta-driving cells (Zhang et al., 2012). Here we report a subset of neurons recorded in stratum oriens of the hippocampal CA1 area in mice. These cells had unique firing patterns, which were very different from those of previously reported neurons. These cells were usually active during theta states and displayed a clock-like firing pattern at the theta band. Therefore, we term them "theta clock-spiking cells." 


\section{Materials and Methods}

Animals. Fifteen male C57BL/6J mice (age range, 4-7 months old; weight range, 25-35 $\mathrm{g}$ at implantation) were used for recording. Animals were singly housed in plastic buckets ( $55 \mathrm{~cm}$ in diameter $\times 42 \mathrm{~cm}$ in height), with free access to food and water, on a $12 \mathrm{~h}$ light/dark cycle. All experimental procedures were conducted in accordance with the Animals Act, 2006 (People's Republic of China).

Microdrive making. A foundation for a recording microdrive was prepared by positioning three 36-pin connector arrays in parallel, as follows: the first and second arrays were secured to both sides of the microdrive base using epoxy glue; and the third array was attached to the second array by a rectangular plastic spacer. The recording microdrive was designed to implant two independently movable electrode bundles of 12 tetrodes and 24 stereotrodes into both sides of dorsal hippocampi, as described in our previous work (Lin et al., 2006). The tetrodes were constructed from four and two, respectively, twisted $13 \mu \mathrm{m}$ nichrome wires (California Fine Wire) bound together by melting their insulation (Czurkó et al., 2011), with gold-plated tips to reduce the electrode impedance to $500-800 \mathrm{~K} \Omega$ at $1 \mathrm{kHz}$.

Surgery. Mice were anesthetized with pentobarbital sodium $(40 \mathrm{mg} /$ $\mathrm{kg}$ ), and their body temperature was kept constant by a small animal thermoregulation device (FHC). The positions for the two bundles of electrodes ( $2.3 \mathrm{~mm}$ posterior and $2.0 \mathrm{~mm}$ lateral to bregma) were measured and marked, and then holes were drilled in the skull at these positions. Afterward, two independently adjustable bundles of 12 tetrodes and 24 stereotrodes were positioned and lowered through the drilled holes into the cortex above the dorsal hippocampi. The gaps between the electrodes and holes were filled with softened paraffin, and the wired microdrive was secured with dental cement.

In vivo recording. Among all 15 animals, 11 were implanted with tetrode wires and the others with stereotrodes. After surgery, mice were normally housed in their home cages (plastic buckets) and were allowed to recover for at least $4 \mathrm{~d}$. Then the connector pin arrays on the microdrive were attached to preamplifiers with extended cables to monitor neuronal signals using a 96-channel Plexon system (http://www.plexon. com). To enable the mouse to move freely when recording, a heliumfilled Mylar balloon was tied to the cables for alleviating the weight of the apparatus and cables. Data acquisition started when the tetrode/stereotrode bundles were advanced slowly toward the hippocampal CA1 region in daily increments of $\sim 0.07 \mathrm{~mm}$ until the tips of the electrodes reached the hippocampal CA1, which was deduced from local field potentials and neuronal activity patterns.

The extracellular signals from electrodes were filtered through the preamplifiers to separate neuronal activity and local field potentials. The spike signals (sampling at $40 \mathrm{kHz}$ ) and the LFP signals (sampling at 1 $\mathrm{kHz}$ ) were filtered on-line at $400-7000$ and $0.7-300 \mathrm{~Hz}$, respectively. Spike waveforms, time stamps, and LFP signals were saved to Plexon data files $\left(^{*}\right.$.plx).

Most of their behaviors, such as sleeping, eating, and quiet waking, were recorded in a home cage, while waking exploration was recorded in a square box $(40 \times 40 \times 20 \mathrm{~cm})$ enriched with toys.

After completion of the experiments, histological staining with $1 \%$ cresyl echt violet was used to confirm the electrode positions.

Spike sorting and cell classification. Individual neurons were identified and sorted by clustering methods in Offline Sorter version 2.8 software (http://www.plexon.com), and performed manually in a threedimensional parameter space. The following two major criteria were used to identify interneurons: $>5 \mathrm{~Hz}$ firing rates and 100-300 $\mu$ s spike durations (Czurkó et al., 2011). Then interspike intervals (ISIs) were used to further isolate theta clock-spiking cells from the other cells.

Detection of theta, gamma, and ripple oscillations. To detect theta oscillations, the original LFP was bandpass filtered $(4-12 \mathrm{~Hz})$. And then a theta $(5-10 \mathrm{~Hz}) /$ delta $(2-4 \mathrm{~Hz})$ ratio was calculated by sliding a $2 \mathrm{~s}$ window. Epochs with more than three consecutive time windows in which the ratio was $>4$ were identified as theta episodes (Csicsvari et al., 1999).

To detect gamma oscillations, the original LFP was digitally bandpass filtered $(30-80 \mathrm{~Hz})$. The gamma power (root mean square) of the fil- tered signal was calculated by sliding a $25 \mathrm{~ms}$ window every $1 \mathrm{~ms}$, and the threshold of detecting gamma episodes was set to 2 SDs above the background mean power (Csicsvari et al., 2003).

To detect ripple oscillations, the original LFP was digitally bandpass filtered $(100-250 \mathrm{~Hz}$ ). The power (root mean square) of the filtered signal was calculated by sliding a $10 \mathrm{~ms}$ window every $1 \mathrm{~ms}$. Epochs with 5 SDs above the background mean power were designated as ripple episodes. And then the time window was moved forward and backward to look for the beginning and the end of each ripple episode, the threshold of which was set to 2 SDs above the background mean power (Csicsvari et al., 1999; Klausberger et al., 2003).

Power spectrum, firing rate analysis. An augmented Dickey-Fuller test was applied to select stationary data for further analysis. A power spectral density analysis was performed on both spike and LFP signals using Welch's averaged periodogram method with a $512 \mathrm{~ms}$ nonoverlapping Hanning window. The discrete spike signals were converted into continuous signals by firing rate histograms with a $1 \mathrm{~ms}$ window.

Theta phase-locking firing analysis. The theta-filtered $(4-12 \mathrm{~Hz}) \mathrm{LFP}$, $y(t)$, was first decomposed into instantaneous amplitude $\rho(t)$ and phase $\phi(t)$ components, as follows:

$$
y(t)=\operatorname{Re}\left(\rho(t) e^{j \phi(t)}\right),
$$

by using a Hilbert transform. Then, given the spike train $\left\{t_{i} \mid i=1,2, \ldots, n\right\}$, spike phase was calculated as follows:

$$
\varphi_{i}=\varphi\left(t_{i}\right)
$$

To evaluate the presence of phase locking, a Rayleigh test (cells that fired $<50$ spikes were excluded) for circular uniformity was performed to compute the significance $(p<0.01)$ of phase locking and the corresponding preferred phases (Siapas et al., 2005). The unit phase was fit with a von Mises distribution.

Spatial firing properties and velocity modulation. Animals were placed into either a circular box ( $55 \mathrm{~cm}$ in diameter $\times 42 \mathrm{~cm}$ in height $)$ or a square box $(40 \times 40 \times 20 \mathrm{~cm}$ in height $)$ with visual cues while recording. Animal behaviors were captured by a digital camera (20 frames/s), and positions were tracked in Cineplex version 3.0 software (http://www. plexon.com). Position data were sorted into $1.5 \times 1.5 \mathrm{~cm}$ pixels. Firing rate maps were constructed (Cacucci et al., 2004) to visualize the positional firing distribution. The spatial information content is defined in bits/spike according to the following formula:

$$
I=\sum_{i}\left(\lambda_{i} / \lambda\right) \log _{2}\left(\lambda_{i} / \lambda\right) P_{i}
$$

where $\lambda_{i}$ is the mean firing rate in each pixel, $\lambda$ is the overall mean firing rate, and $P_{i}$ is the probability of the animal to be in pixel $i$ (Rochefort et al., 2011). Locomotion velocity and firing rate were averaged into $1 \mathrm{~s}$ bins. Spearman correlation coefficients were computed between the velocity and firing rate of recorded cells.

\section{Results}

\section{Theta rhythmic clock-like activity of hippocampal CA1 theta clock-spiking cells}

We recorded five theta clock-spiking cells in the hippocampal CA1 area in five mice, respectively. These cells fired predominately in theta states during waking exploration or rapid eye movement (REM) sleep, but stayed almost silent during slowwave sleep (SWS; Figs. 1A,2). These cells normally fired one spike per theta cycle; therefore, they represented a typical clock-spiking pattern with theta rhythm (Figs. $1 B, 2$ ). The ISI histograms of these cells are Gaussian distributions centered at the theta frequency (Figs. 1C, 2; false discovery rate (FDR) correction for five comparisons, $q>0.1$; Lilliefors test). Multiple peaks in the autocorrelograms indicate a periodic firing in the theta frequency range (Figs. 1C, 2; average interpeak interval, $95.0 \pm 7.9 \mathrm{~ms}$; $n=5$ ). However, of the five recorded theta clock-spiking cells, 


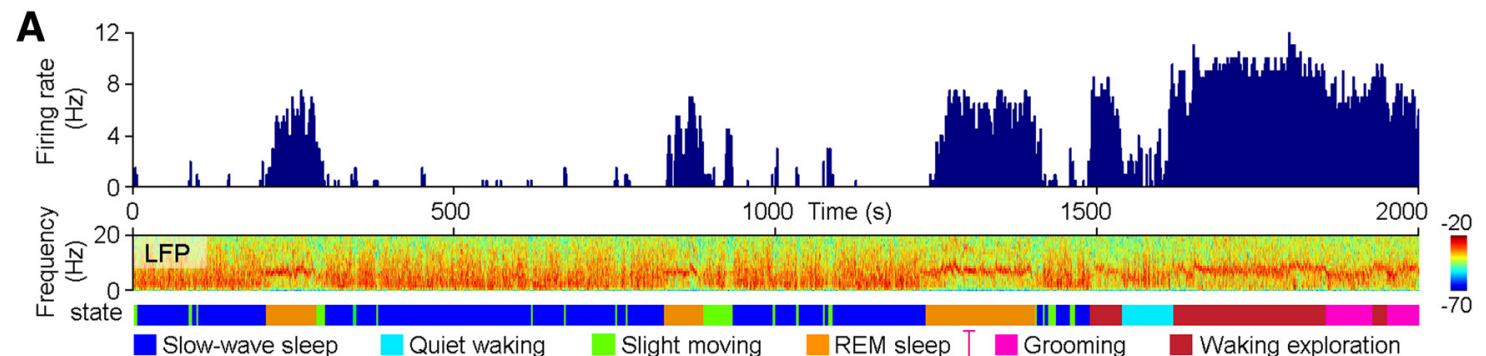

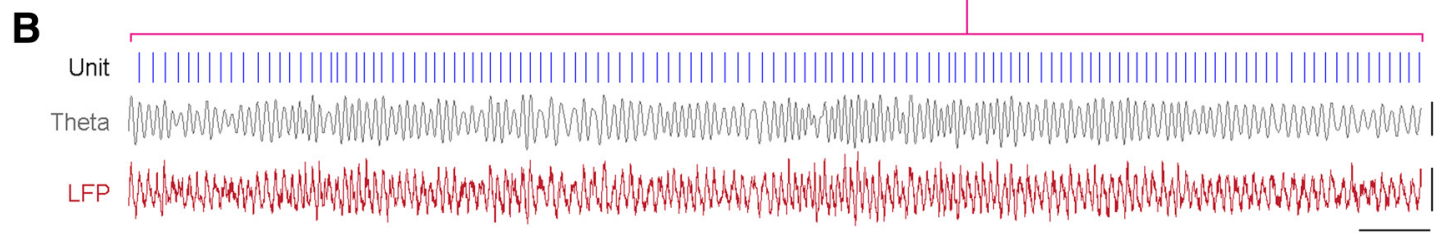
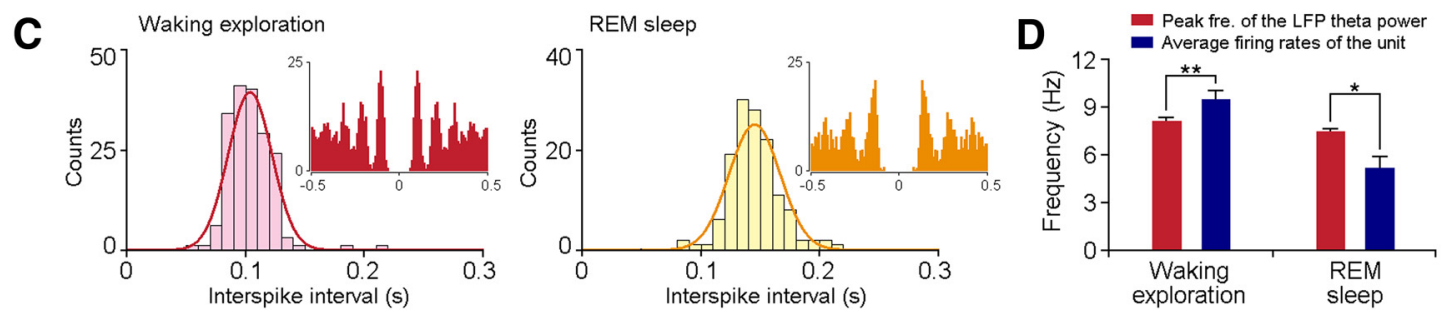

Figure 1. The firing pattern of theta clock-spiking cells. $A, A$ firing rate histogram of a theta clock-spiking cell from a $2000 \mathrm{~s}$ recording (top) and a power spectrogram of the corresponding hippocampal CA1 LFP (bottom). The colored bar at the bottom indicates various behavioral states. B, A zoomed-in representation of the REM sleep state from above. Note a theta rhythmic clock-like firing pattern. Scales: theta, $0.3 \mathrm{mV}$; LFP, $0.5 \mathrm{mV}$; time, $1 \mathrm{~s}$. C, ISI histograms of the cell during $20 \mathrm{~s}$ of the waking exploration state (left) and $20 \mathrm{~s}$ of the REM sleep state (right). Note the Gaussian distribution in both. Insets are autocorrelograms. D, Significant differences between the average firing rates of the theta clock-spiking cells and the peak frequencies of the power spectra of the corresponding LFP theta. Error bars represent the SD. ${ }^{*} p<0.05,{ }^{* *} p<0.01$; for waking exploration, $n=5$; for REM sleep, $n=4$. fre., Frequency.
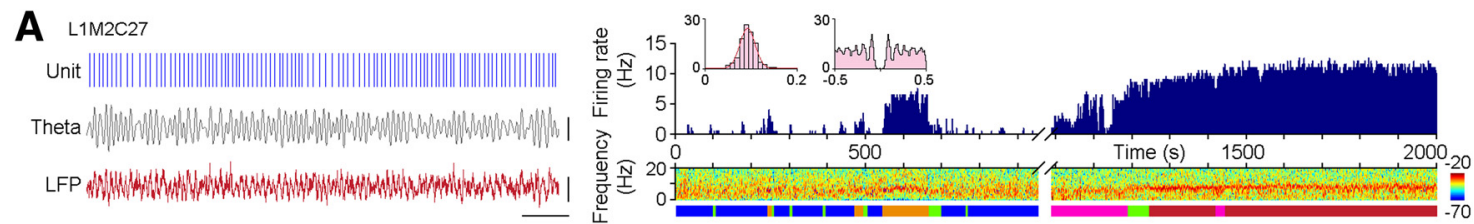
B Linscol
Unit ||||||||||||||||||||||||||||||||||||||||||||||||||||||||||||||||||||||||||||||||||||||||||||||||

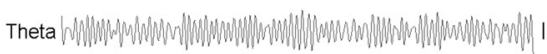

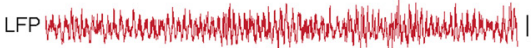

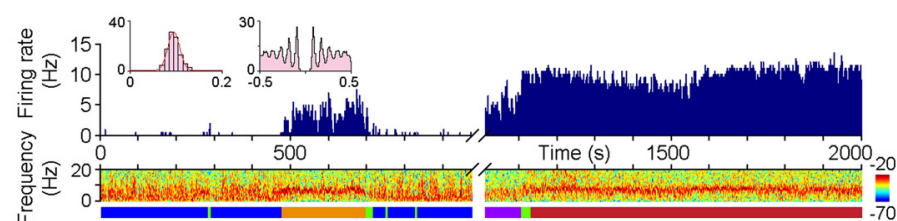
C $23 \mathrm{M} 401$
Unit |||||||||||||||||||||||||||||||||||||||||||||||||||||||||||||||||||||||||||

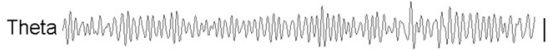

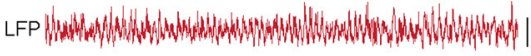

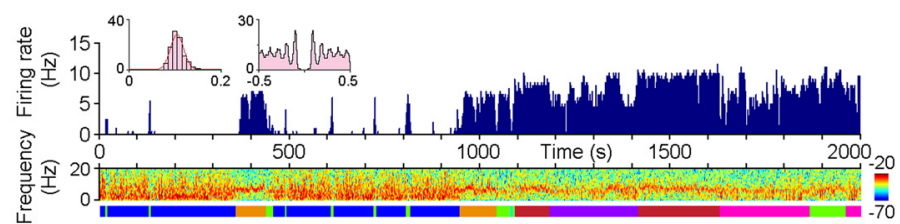
D $\mathrm{LAM}_{\mathrm{M}} \mathrm{CO}$
Unit |||||||||||||||||||||||||||||||||||||||||||||||||||||||||||||||||||||||||||||||||||

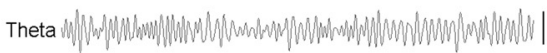 LFP is

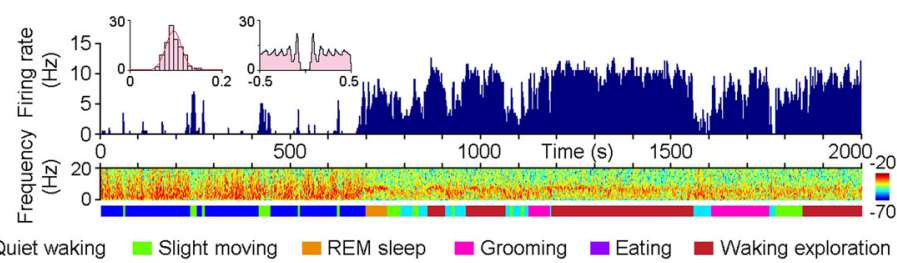

Figure 2. The other four theta clock-spiking cells. $\boldsymbol{A}-\boldsymbol{D}$, Each panel represents one cell. Left panels show the firings of theta clock-spiking cells during waking exploration state. Scales: theta, $0.2 \mathrm{mV}$; LFP, $0.4 \mathrm{mV}$; time, $1 \mathrm{~s}$. Right panels show firing rate histograms of the cells and power spectrograms of the corresponding hippocampal CA 1 LFPs. The colored bars at the bottom indicate various behavioral states. Insets are ISI histograms with Gaussian fitting and autocorrelograms, both during waking exploration state. 
A
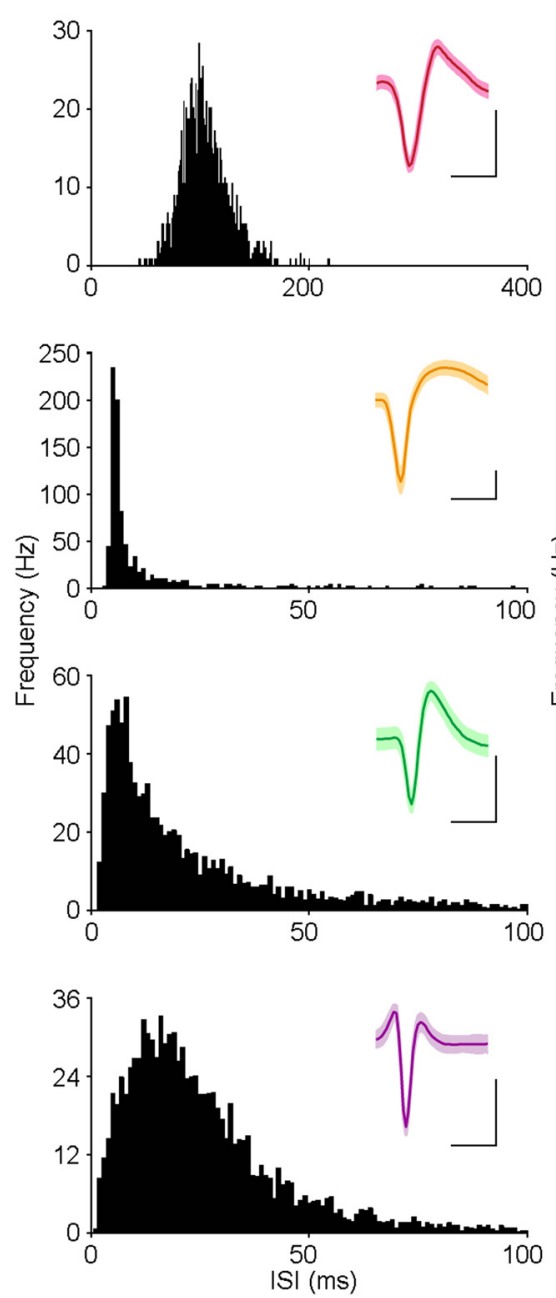

B

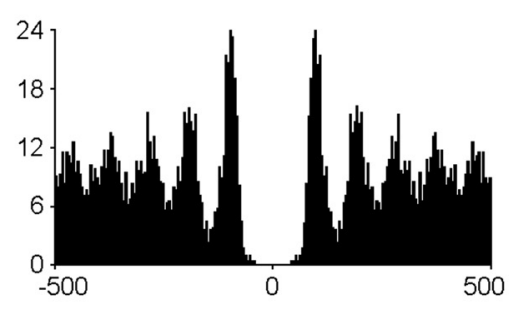

C
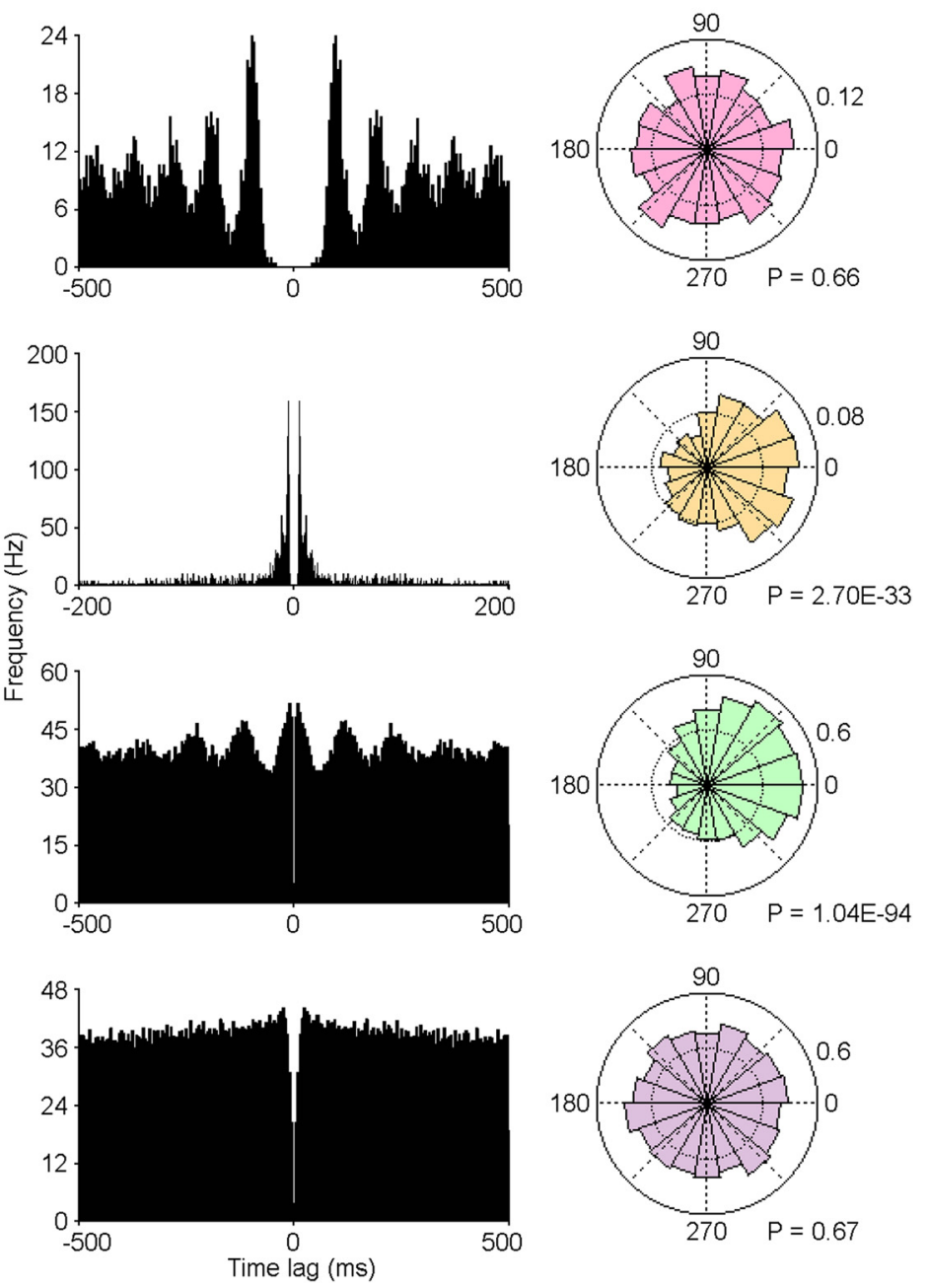

Figure 3. Spiking properties of four types of CA1 cells. $A$, ISI distributions of a theta clock-spiking cell, a complex-spiking cell, a theta-locked interneuron, and a theta-unlocked interneuron (top to bottom); insets are the extracellular waveforms (mean \pm SD; 500 waveforms were calculated for each cell). ISI bin width, $1 \mathrm{~ms}$. Scales: $0.1 \mathrm{mV}, 0.5 \mathrm{~ms}$. B, Autocorrelograms of the corresponding cells in $\boldsymbol{A}$. Bin widths: $0.5 \mathrm{~ms}$ for the complex-spiking cell; $5 \mathrm{~ms}$ for the others. $\boldsymbol{C}$, Spike phase distributions of the corresponding cells in $\boldsymbol{A}$ related to LFP theta oscillations.

four show no significant phase relationship to LFP theta (FDR correction for five comparisons, $q>0.05$; Rayleigh test).

Additionally, we calculated the firing rates of these theta clock-spiking cells under different theta states. Interestingly, the average firing rate during waking exploration was $9.47 \pm 0.53 \mathrm{~Hz}$ (Fig. $1 D ; n=5$ ), which was slightly higher than the peak frequency of the power spectrum of the corresponding hippocampal LFP theta rhythm $(8.09 \pm 0.22 \mathrm{~Hz} ; n=5$; repeated-measures unbalanced ANOVA: $p<0.05, F_{(1,3)}$ (Measurement) $=29.17$; $p<0.01, F_{(1,3)}$ (Behavior) $=85.52 ; p<0.01, F_{(1,3)}$ (Interaction) $=37.19 ; p<0.01, t_{(4)}=6.95$, paired $t$ test with Bonferroni correction). On the other hand, the average firing rate during REM sleep was $5.18 \pm 0.66 \mathrm{~Hz}$, which was lower than the peak frequency of the LFP theta rhythm $(7.42 \pm 0.18 \mathrm{~Hz} ; n=4 ; p<$ $0.05, t_{(3)}=-6.38$, paired $t$ test with Bonferroni correction).

Identification of theta clock-spiking cells from other cells In addition to the five theta clock-spiking cells, we recorded various neurons in the CA1 area. Among other 508 well isolated units, there were 44 theta-locked interneurons and 39 thetaunlocked interneurons in stratum oriens and stratum pyramidale, as well as 425 complex-spiking cells in stratum pyramidale.
Relatively, the proportion of the theta clock-spiking cells was extremely low. Usually, more than one neuron could be separated simultaneously from a tetrode, but theta clock-spiking cells were never recorded together with other neurons from one tetrode. This suggested that these cells might be located in areas where neurons were sparsely distributed. Furthermore, ripples and theta oscillations were observed on the tetrodes with theta clock-spiking cells recorded. Compared with LFPs in stratum pyramidale, ripples on those five tetrodes were smaller, and theta oscillations had a 3-24 ms delayed phase, which indicated that the somata of these theta clock-spiking cells were probably located in stratum oriens.

Different from other types of cells in CA1, which showed Poisson distribution, theta clock-spiking cells showed Gaussian ISI distribution (Fig. 3A). Therefore, theta clock-spiking cells could be easily identified from other types of neurons in CA1, based just on their peak interval of ISI distributions (Fig. 4; Kruskal-Wallis test: $p<0.001, \chi_{3}^{2}=16.77 ; p<0.01$, post hoc Dunn's test). In addition, firing rates during exploration enabled us to distinguish theta clock-spiking cells from complex-spiking cells (Fig. 4; Kruskal-Wallis test: $p<0.001, \chi_{3}^{2}=218.7 ; p<0.01$, post hoc 


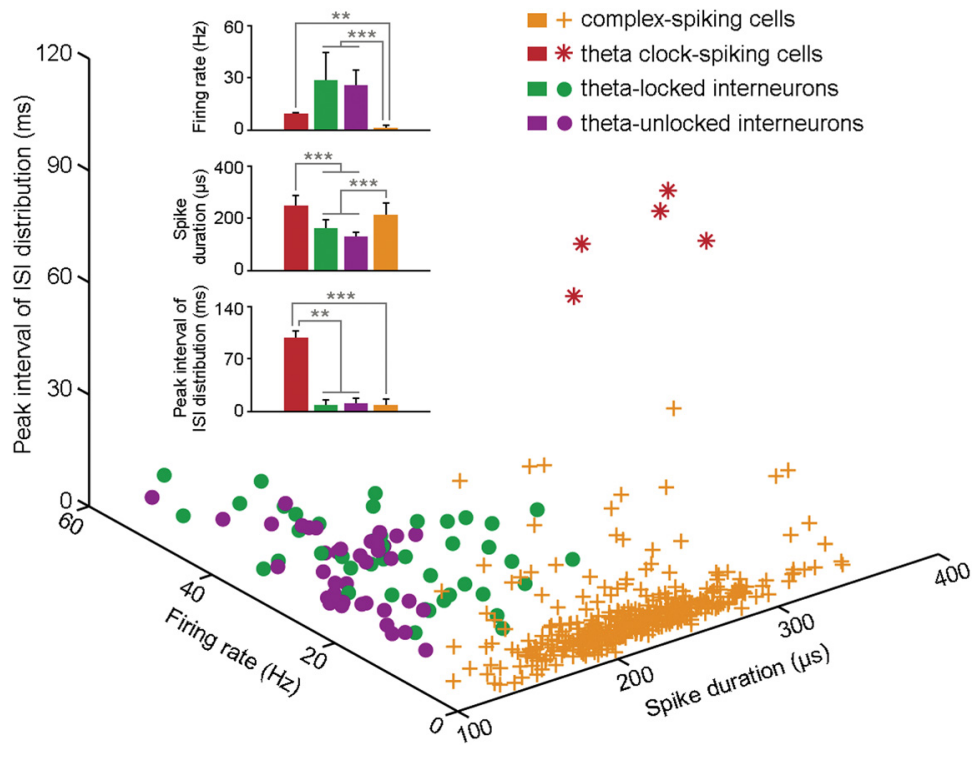

Figure 4. Classification of four types of cells recorded in CA1. Each symbol represents one cell. $x$-axis, Durations of extracellular waveforms measured at $1 /$ e negative peak; $y$-axis, firing rates; $z$-axis, peak intervals of ISI distributions. Insets, Summary data for firing rate, spike duration, and peak interval of ISI of the four types of neurons. Error bars represent SD. ${ }^{* *} p<0.01,{ }^{* * *} p<0.001$. For theta clock-spiking cells, $n=5$; for theta-locked interneurons, $n=44$; for theta-unlocked interneurons, $n=39$; for complexspiking cells, $n=425$.

Dunn's test), and spike durations enabled us to separate theta clock-spiking cells from interneurons (Fig. 4; Kruskal-Wallis test: $p<0.001, \chi_{3}^{2}=141.7 ; p<0.001$, post hoc Dunn's test).

In addition, theta clock-spiking cells were not phase locked to gamma oscillations (FDR correction for five comparisons, $q>$ 0.1 ; Rayleigh test) during waking exploration or REM sleep, and were not correlated to ripple events during SWS sleep. These cells showed nonspatial preference, with spatial information of $<0.15$ bit/spike, much lower than those reported in place cells in mice (Cacucci et al., 2007; Rochefort et al., 2011; Zhang et al., 2014). However, the firing rates of these cells were significantly related to locomotion velocity (Bonferroni correction with five comparisons, $p<0.005$; Spearman's $\rho$ test).

\section{Discussion}

In this study, we recorded 5 theta clock-spiking cells from among a total of 513 hippocampal cells in 15 mice. However, these five cells showed uniform in vivo firing patterns, as they fired almost exclusively during theta states, fired one spike per theta cycle, and displayed similar firing rate properties and ISI distribution. Hence, we recognize these cells as being from the same population even though we could not confirm their morphological or immunological characteristics using the multichannel in vivo recording method. Although five cells may seem to be too small a sample, considering that the somata of these five cells were probably scattered in stratum oriens, and they were never recorded with other neurons from one tetrode, we reason that the total number of this type of cell in hippocampus is very low. According to previous studies, interneurons represent only $\sim 10 \%$ of the total number of hippocampal neurons (David et al., 2006) yet contain diverse cell types (Freund and Buzsáki, 1996). Therefore, it is highly possible that the population of a specific type of neuron, such as the theta clock-spiking cell, is quite low.

Clock-spiking cells were first reported in the optic lobes of insects in 1965 (Kuiper and Leutscher-Hazelhoff, 1965). These cells are characterized by a consistent and repetitive firing pattern at a very constant rate. As a result, their interspike interval histograms fol- low Gaussian distributions (Kuiper and Leutscher-Hazelhoff, 1965). However, since discovery, further relevant studies have been rare, and the functional understanding of these cells has been limited because of their unique and uncommon firing patterns (Burtt and Patterson, 1970; Moro and Huotari, 1998).

Our encounter with such theta clockspiking cells in the hippocampus poses some questions about the biological roles of this type of cell. One possibility is that the firing pattern of these cells contributes to hippocampal self-generated theta oscillations, since several intrinsic, atropineresistant theta generators have been found in CA1 using isolated rat hippocampal preparations (Traub et al., 1989; Goutagny et al., 2009). However, our recorded cells show a different frequency of firing rate from the peak frequency of LFP theta, suggesting that their involvement in the theta generation is highly unlikely. Second, their activity may contribute to the theta phase precession in place cells ( $\mathrm{Sk}$ aggs et al., 1996; Huxter et al., 2003). A recent study on the subthreshold membrane potentials of hippocampal place cells showed that when animals ran across place fields, the phase precession effect resulted from phase precession of intracellular membrane theta oscillations in relation to the extracellular LFP theta rhythm (Harvey et al., 2009; Leung, 2011). In the hippocampus, some of the cells that represent sequence memories are responsible for temporal coding (MacDonald et al., 2011). Our observations demonstrate that the theta clock-spiking cells have a clock-like periodic firing pattern during the awake theta state, and the clocking frequency is higher than the theta rhythm of LFPs. Therefore, we speculate that the activity of these theta clockspiking cells may provide an overall time reference for the theta phase precession of intracellular membrane potential oscillations in place cells. But, unlike place cells, neither the spike timing nor the theta phases of theta clock-spiking cells encode spatial information. Notably, there are correlations between the firing of these theta clock-spiking cells and the locomotion speed of animals. Seeing that the firing of theta clock-spiking cells follows theta rhythm, this could be caused by the correlation between theta oscillations and speed, as has been reported in other studies (Hinman et al., 2011; Newman et al., 2013; Richard et al., 2013).

\section{References}

Burtt ET, Patterson JA (1970) Internal muscle in the eye of an insect. Nature 228:183-184. CrossRef Medline

Cacucci F, Lever C, Wills TJ, Burgess N, O’Keefe J (2004) Theta-modulated place-by-direction cells in the hippocampal formation in the rat. J Neurosci 24:8265-8277. CrossRef Medline

Cacucci F, Wills TJ, Lever C, Giese KP, O'Keefe J (2007) Experiencedependent increase in CA1 place cell spatial information, but not spatial reproducibility, is dependent on the autophosphorylation of the alphaisoform of the calcium/calmodulin-dependent protein kinase II. J Neurosci 27:7854-7859. CrossRef Medline

Csicsvari J, Hirase H, Czurkó A, Mamiya A, Buzsáki G (1999) Oscillatory coupling of hippocampal pyramidal cells and interneurons in the behaving rat. J Neurosci 19:274-287. Medline

Csicsvari J, Jamieson B, Wise KD, Buzsáki G (2003) Mechanisms of gamma 
oscillations in the hippocampus of the behaving rat. Neuron 37:311-322. CrossRef Medline

Czurkó A, Huxter J, Li Y, Hangya B, Muller RU (2011) Theta phase classification of interneurons in the hippocampal formation of freely moving rats. J Neurosci 31:2938-2947. CrossRef Medline

David A, Andersen P, Morris R, Bliss T, O'Keefe J (2006) The hippocampus book. New York: Oxford UP.

Freund TF, Buzsáki G (1996) Interneurons of the hippocampus. Hippocampus 6:347-470. Medline

Goutagny R, Jackson J, Williams S (2009) Self-generated theta oscillations in the hippocampus. Nat Neurosci 12:1491-1493. CrossRef Medline

Harvey CD, Collman F, Dombeck DA, Tank DW (2009) Intracellular dynamics of hippocampal place cells during virtual navigation. Nature 461: 941-946. CrossRef Medline

Hinman JR, Penley SC, Long LL, Escabí MA, Chrobak JJ (2011) Septotemporal variation in dynamics of theta: speed and habituation. J Neurophysiol 105:2675-2686. CrossRef Medline

Huxter J, Burgess N, O'Keefe J (2003) Independent rate and temporal coding in hippocampal pyramidal cells. Nature 425:828-832. CrossRef Medline

Klausberger T, Magill PJ, Márton LF, Roberts JD, Cobden PM, Buzsáki G, Somogyi P (2003) Brain-state- and cell-type-specific firing of hippocampal interneurons in vivo. Nature 421:844-848. CrossRef Medline

Kuiper JW, Leutscher-Hazelhoff JT (1965) High-precision repetitive firing in the insect optic lobe and a hypothesis for its function in object location. Nature 206:1158-1160. Medline

Leung LS (2011) A model of intracellular $\theta$ phase precession dependent on intrinsic subthreshold membrane currents. J Neurosci 31:12282-12296. CrossRef Medline

Lin L, Chen G, Xie K, Zaia KA, Zhang S, Tsien JZ (2006) Large-scale neural ensemble recording in the brains of freely behaving mice. J Neurosci Methods 155:28-38. CrossRef Medline

Lin L, Chen G, Kuang H, Wang D, Tsien JZ (2007) Neural encoding of the concept of nest in the mouse brain. Proc Natl Acad Sci U S A 104:60666071. CrossRef Medline

MacDonald CJ, Lepage KQ, Eden UT, Eichenbaum H (2011) Hippocampal "time cells" bridge the gap in memory for discontiguous events. Neuron 71:737-749. CrossRef Medline

Moro SD, Huotari M (1998) Clock-spiking cells not only in the eye of the fly, but also in the antenna! Acta Neurobiol Exp (Wars) 58:277-281. Medline

Newman EL, Gillet SN, Climer JR, Hasselmo ME (2013) Cholinergic blockade reduces theta-gamma phase amplitude coupling and speed modulation of theta frequency consistent with behavioral effects on encoding. J Neurosci 33:19635-19646. CrossRef Medline

O'Keefe J, Dostrovsky J (1971) The hippocampus as a spatial map. Preliminary evidence from unit activity in the freely-moving rat. Brain Res 34: 171-175. CrossRef Medline

Quiroga RQ, Reddy L, Kreiman G, Koch C, Fried I (2005) Invariant visual representation by single neurons in the human brain. Nature 435:11021107. CrossRef Medline

Richard GR, Titiz A, Tyler A, Holmes GL, Scott RC, Lenck-Santini PP (2013) Speed modulation of hippocampal theta frequency correlates with spatial memory performance. Hippocampus 23:1269-1279. CrossRef Medline

Rochefort C, Arabo A, André M, Poucet B, Save E, Rondi-Reig L (2011) Cerebellum shapes hippocampal spatial code. Science 334:385-389. CrossRef Medline

Siapas AG, Lubenov EV, Wilson MA (2005) Prefrontal phase locking to hippocampal theta oscillations. Neuron 46:141-151. CrossRef Medline

Skaggs WE, McNaughton BL, Wilson MA, Barnes CA (1996) Theta phase precession in hippocampal neuronal populations and the compression of temporal sequences. Hippocampus 6:149-172. CrossRef Medline

Traub RD, Miles R, Wong RK (1989) Model of the origin of rhythmic population oscillations in the hippocampal slice. Science 243:1319-1325. CrossRef Medline

Zhang L, Chen G, Niu R, Wei W, Ma X, Xu J, Wang J, Wang Z, Lin L (2012) Hippocampal theta-driving cells revealed by Granger causality. Hippocampus 22:1781-1793. CrossRef Medline

Zhang S, Schönfeld F, Wiskott L, Manahan-Vaughan D (2014) Spatial representations of place cells in darkness are supported by path integration and border information. Front Behav Neurosci 8:222. CrossRef Medline 